\title{
COMUNICAÇÕES
}

\section{Qualidade fisiológica e sanitária de sementes de girassol produzidas na região de Timon, Maranhão}

\author{
Delineide Pereira Gomes ${ }^{1}$, José Magno Martins Bringel ${ }^{1}$, Myrna Furtado Hilal Moraes ${ }^{1}$, Josilda Junqueira Ayres \\ Gomes $^{1}$, Regina Maria Villas Bôas de Campos Leite ${ }^{2}$
}

\begin{abstract}
${ }^{1}$ Universidade Estadual do Maranhão, Centro de Ensino de Ciências Exatas e Naturais, Cidade Universitária Paulo VI, s/n, Tirirical, São Luís, MA, 65055-098, UNICEUMA e- mail: magnobringel@ cecen.uema.br, ${ }^{2}$ Embrapa Soja, Londrina- PR, e-mail: regina@ cnpso.embrapa.br Autor para correspondência: José Magno Martins Bringel

Data de chegada: 01/07/2005. Aceito para publicação em: 30/09/2005.
\end{abstract}

O girassol é uma oleaginosa que apresenta características agronômicas importantes, como maior resistência à seca, ao frio e ao calor, que a maioria das espécies normalmente cultivadas no Brasil. Apresenta ampla adaptabilidade a diferentes condições edafoclimáticas e seu rendimento é pouco influenciado pela latitude, pela altitude e pelo fotoperíodo.

A expansão da cultura do girassol pode ser prejudicada, entre outros fatores, pela qualidade fisiológica das sementes e pela presença de doenças causadas por vírus, bactérias e fungos. Desta forma, o objetivo do trabalho foi avaliar a qualidade fisiológica e sanitária de sementes de girassol produzidas na região de Timon, Estado do Maranhão.

O experimento de campo foi conduzido na Fazenda Cantinho Dorilândia, município de Timon, MA (55'43" latitude sul e $42^{\circ} 49^{\prime} 8^{\prime \prime}$ longitude oeste; altitude $69 \mathrm{~m}$ ). As análises de sementes foram desenvolvidas nos laboratórios de Patologia de Sementes, pertencente ao Núcleo de Biotecnologia Agronômica, e de Análise de Sementes (LAS) da Universidade Estadual do Maranhão - UEMA, em São Luís, MA. As sementes colhidas foram submetidas à análise sanitária em laboratório. Para se avaliar a qualidade fisiológica, as amostras foram submetidas aos testes de vigor e de germinação.

Os resultados da análise sanitária (Tabela 1) demonstraram a presença dos principais patógenos de girassol, Alternaria spp. e Sclerotinia sclerotiorum, nas sementes dos genótipos testados, bem como de outros fitopatógenos. De maneira geral, foram observados baixos índices de sementes infectadas com Sclerotinia sclerotiorum (Tabela 1), exceto para o genótipo ACA 885,

Tabela 1. Incidência (\%) de fungos em sementes de 12 genótipos de girassol, detectados pelo método do papel de filtro.

\begin{tabular}{|c|c|c|c|c|c|c|c|c|c|c|c|c|}
\hline \multirow[t]{2}{*}{ FUNGOS } & \multicolumn{12}{|c|}{ GENÓTIPOS (\%) } \\
\hline & Catissol & Nutrissol & M 734 & Agrobel & ACA & Embrapa & Hélio & ACA & Hélio & $\mathbf{V}$ & $\mathbf{V}$ & $\mathrm{ACA}$ \\
\hline & 01 & & & 960 & 884 & 122 & 250 & 872 & 251 & 90064 & 80198 & 885 \\
\hline Alternaria spp. & $20 *$ & 25 & 14 & 19 & 30 & 10 & 10 & 21 & 27 & 9 & 29 & 2 \\
\hline Aspergillus spp. & 0,25 & 0,25 & 0,5 & 3 & 1 & 1 & 1 & 0,25 & 3 & 0 & 0,25 & 2 \\
\hline Botrytis sp. & 0 & 0,25 & 0 & 0,25 & 2 & 0 & 0 & 0 & 0 & 0 & 0 & 0,5 \\
\hline Chaetomium sp. & 0,25 & 0 & 0 & 0,25 & 1 & 0 & 0,5 & 0,25 & 0 & 0 & 0 & 0,5 \\
\hline Cladosporium sp. & 0 & 0 & 1 & 0 & 0 & 0 & 0 & 0 & 0 & 0 & 0,25 & 0 \\
\hline Curvularia sp. & 21 & 14 & 20 & 30 & 20 & 7 & 11 & 22 & 7 & 15 & 26 & 9 \\
\hline Dreschelera sp. & 20 & 29 & 17 & 31 & 15 & 57 & 21 & 23 & 18 & 31 & 12 & 17 \\
\hline Fusarium sp. & 63 & 59 & 49 & 43 & 49 & 27 & 75 & 59 & 47 & 52 & 41 & 40 \\
\hline Penicillium sp. & 0,25 & 0,25 & 1 & 4 & 0 & 7 & 0,25 & 2 & 7 & 0 & 0 & 37 \\
\hline Phoma sp. & 3 & 1 & 0,5 & 8 & 4 & 0 & 3 & 0,5 & 0,25 & 0 & 0 & 10 \\
\hline Rhizoctonia sp. & 1 & 0 & 0,25 & 0 & 0,25 & 0,25 & 0,25 & 0 & 0 & 0 & 0,25 & 1 \\
\hline Rhizopus sp. & 0 & 0 & 4 & 0 & 0,25 & 0 & 0 & 0 & 0 & 0 & 1 & 0,25 \\
\hline Sclerotinia sclerotiorum & 3 & 2 & 4 & 0,5 & 2 & 4 & 4 & 4 & 4 & 2 & 4 & 17 \\
\hline Trichoderma sp. & 0 & 0 & 0 & 1 & 0,25 & 0,25 & 0 & 0 & 0,25 & 2 & 0,25 & 3 \\
\hline
\end{tabular}


que apresentou o maior percentual de sementes com este fungo $(17 \%)$. O período de incubação visando a detecção de $S$. sclerotiorum é maior do que nos demais (15 dias ao invés de 7), devido à formação dos escleródios, principal característica morfológica do fungo. Apresentar de não apresentar os maiores índices, observa-se que o genótipo ACA 885 foi suscetível a quase todos os fitopatógenos, com exceção do gênero Cladosporium (Tabela 1), o que pode indicar uma baixa qualidade sanitária de suas sementes. A presença dos contaminantes Aspergillus spp, Penicillium sp. e Rhizopus sp. pode ser ao fato de não se ter realizado o pré-tratamento das sementes.

Os resultados da qualidade fisiológica demonstraram que os genótipos V 90064, ACA 885, V 80198, ACA 884 e Agrobel 960 apresentaram melhor qualidade fisiológica. As sementes do genótipo Catissol 01, apesar de não apresentarem um bom índice de vigor e de não estarem dentro do padrão de germinação do girassol, não resultaram em plântulas infectadas, com vantagem no aspecto de sanidade em relação aos demais genótipos. Os genótipos Hélio 250 e Embrapa 122 apresentaram baixos índices de vigor de sementes e germinação de plântulas normais e altos índices de plântulas anormais e infectadas, além de apresentarem os maiores índices de sementes mortas ( $43 \%$ e $39 \%$, respectivamente).

Os fungos detectados não tiveram influência sobre o vigor e germinação de plântulas normais. Isto pode ser constatado ao se observar que os índices de vigor e germinação de plântulas normais dos genótipos ACA 884, ACA 885, M 734 e Agrobel 960 foram relativamente altos, apesar dos mesmos apresentarem o maior número de patógenos associados às suas sementes. Entretanto, pode-se associar que os baixos percentuais de vigor dos genótipos Catissol 01, Hélio 251 e os baixos índices de plântulas normais dos genótipos Hélio 250 e Nutrissol estão relacionados com os altos percentuais de sementes portadoras de Fusarium sp.. 